\title{
The Synergy between Culture and Society in the Eradication of Child Molestation in Nigeria
}

\author{
Hannah Modupe Akpodiete, PhD* \\ Department of Theatre Arts, Delta State University Abraka. Delta State, Nigeria. \\ *Corresponding Author: Hannah Modupe Akpodiete, Department of Theatre Arts, Delta State \\ University Abraka. Delta State, Nigeria.

\begin{abstract}
The menace of child molestation has become a recurrent decimal in Nigeria that it has drawn the attention of both the local and International communities. Historically, culture has been taken as the way of life of the people. A holistic approach was adopted using the qualitative research methodology in selecting from the proponents of the three major ethnic group for the study namely, the Igbos, Hausa and the Yoruba's. Findings from the study have it that there were variations in the socio-cultural values of the 3 major ethnic groups in the handling and training of children. These variations include the total training of children in the Yoruba tribe from kindergarten years to adulthood along the cultural values of the Yoruba race. The case of the Igbos was quite similar but with little or no emphasis on cultural values from childhood to adulthood. A cursory look at the Hausa culture revealed that cultural values of this ethnic groups are profound but tends towards religious inclinations in their approach of raising children. These variations however transcend to relationship problems in the society. This however made the case of child molestation to be treated with utmost attention in the South Western region as well as the South Eastern region of Nigeria. The Northern part is however handling the case from the angle of religion. The study therefore recommends that child molestation must be seen and treated as violence against children so that there can be a cross cultural exchange of values geared towards a resolution of this problem in Nigeria.
\end{abstract}

\section{INTRODUCTION}

Freedom from threat to life, respect for the dignity and typical privileges of all members of the family, fall within the agenda of the United Nations. These ethics are basic requirement of decent societies. Our approaches to stop this menace, whether government orindividualywired is included in the strong convictions or dangerous practices, begins with the safety of our younger citizens. Each child is entitled to freedom from all manners of threats. Apart from collective wisdom and basic ethics; it is a global legal requirement, as stated in the Convention on the Privileges of the Child, the world's most widely accepted human rights treaty.

Edu and Edu (1999) stated that child abuse is a deliberate maltreatment of a child. Such maltreatment according to them can include acts of commission, abuse, omission, and neglect. A short definition of child abuse is reduced to life-threatening, physical violence, including severe beatings which inflicted injury on children by the adult members of the community.

Child molestation represents a new sociocultural matter in the African society. Several abuses have been noted following physical force such as many bruises in uncommon parts, burns, wound in many parts of the body, vaginal and anal tears, severe injury leading to child's mortality have been made known in several occasions.

The need for good change is important, but for now, violence remains a prevalent spectacle that impairs the life of millions of children, affects entire communities and smothers the future of youth and deterworkablegrowth and common advancement. Violence against girls' and boys' involved sections of age, race, culture, wealth and geographical places. It can evolve in the home, on the streets, in schools, in the workplace, in detention centres and in institutions which caters for children. For millions of girls and boys, in the world over, childhood is described by one word: fear. labour, neglect, intimidation, exploitation and so many others. Such violence also has dire consequences. It alters child development and raises diverse health challenges, poor school performance and long-term welfare need. It is often linked to poverty and scarcity, and act as a constraint on the potential of individuals and nations. 


\subsection{The Origin of Culture}

Culture emanated from the primordial practices of the primitive age. Man's inward desire to satisfy his predisposition for survival was characterised by the ecological adjustment of food and seeking protection for life. Hence culture transformed the lives of the primitive society by altering man's immediate habitat, support the productions of food, clothing, and shelter by employing the psychosocial activities to delineate social stratums of the society with distinct cultural traditions. The expansion of social groups has brought about the development of man's zeal for survival, menacing territories and aggressively seeking livelihood, security and protection of life within the cultural strata. Society satisfaction is the bane of cultural alienation among families in the modern society. Thus, such cultural transformation has led to the deviation, abandonment and nonconforming to the cultural values, cultural norms, cultural etiquette, cultural beliefs, and cultural practices. Furthermore, the deviation from these culturally acceptable norms has brought about the imbibing of this hydra-headed menace of child molestation. The advent of culture as a thought and as an absolute medium tolimit child molestation emerges in a very intricate way, merges in two general methods first, the acknowledgement of the practical departure of certain moral and intellectual activities from the driven inspiration of a new kind of society; second, the importance of these activities, as a court of human appeal, to be set over the processes of practical social judgement and yet to offer itself as a modifying and rallying alternative. But, in both senses, culture was not seen by the populace as a response towards reducing child molestation problems. Having a thorough and thorough understanding of the ability of culture to proffer solution to such social issues is a fundamental issue that must be employed by both the social class, the government, parents and the society in resolving this social menace.

\subsection{The Concept of Child Molestation}

Though the word child molestation or child abuse has been in existence in the arts, sciences and literary works for ages. Its historical recorded format is dated to 1962, when it received public attention and acceptance due to a seminal work titled "The abused child syndrome by Kempe et, al" (Kemp CH et al 17-24)Child molestation can be categorised as physical abuse, sexual abuse, emotional abuse, and neglect of different forms. Also, child abuse can also be a physical, sexual, or emotional abuse or neglect of a child or children, especially by a parent or guardians. It may include any act or failure to act by a parent or other guardians that turns in real or likely harm to a child, and can occur in a child`s home, or in an organization, schools or settlementsor anywhere a child mixes up. The terms child abuse and child harassment are sometimes used intermittently, but some researchers make a distinction between them, treating child abuse as an umbrella term to cover abandonment, abuse and trading.

There is no commonlyrecognizeddescription of childmolestation as a result of the differences in the observation of what usually is suitable as abusive or not. The African network for deterrenceand defense against child abuse and neglect defines child abuse as the planned, unplanned or wellintended acts which jeopardize the physical health, emotional, moral and the educational well-being of children.

Child abuse is any act of oversight or directive, physical or psychological abuse or abandonment of a child by its parent, guardian, caregivers or other adults that may jeopardize the child's physical, emotional health and development. Here, improperlyabusing a child or selfishly making an biased use of a child's services by adults accountable for the child makes child abuse thus the adult may not be linked to the child but a person in whose care the child is left can be a molester. This may include the knowledge managers, healthcare workers, day care workers, or other responsible adults.

Studies reveal that childhood knowledges set a serious groundwork for the entire life development. Girls appear to be especially susceptible due to certain cultural practices, labelling, and cultural and religious beliefs, which put them at risk, particularly in African societies. The specific problems confronting girls in Nigeria include family abuse and domestic violence. Others are sexual abuse, rejection, neglect, genital mutilation, forced and early marriage. There are cases of victimisation on feeling of witchcraft, girl-child murder, forced prostitution, and child labour. (Aderinto, 2010; Alabi et al., 2013; Togunde\& Carter, 2008). 


\subsection{The Place of the Family in Child Molestation}

Family is a general word though it might have different elucidations depending on the family configuration. The Census Agency" defined the family as householder and one or more persons living in the same family who are related to the householder by birth, marriage, or adoption" (Census1990)

The family is the lowest part of the society stratum and the most important arm. It is at this level that interpersonal communication is most effective. Members air freely their thoughts, expresses their frustration, fears, pains, shares their joys and relate freely without much reservation. Furthermore, trust for one another is at its peak because of the upbringing ties and the relationship within the nuclear family which encourages strong bonding. As the most important part of the society, is the first school where a child istutored, educated, and exposed to the basic principles of life and the society. Hence the family shielded, sheltered, preserved, provided, and guarded the child in the acceptable cultural norms of the family, community, and humanity mainly. Thus, provided the traditional basic needs of the child which include food, clothes and shelter.The family plays an essential role in a child's life, because it builds the foundation on which the societal structure is erected. Emphasing this fact Zabriskie and McCornmick (2001) stated that "families are goal-getters, sound, dynamic, and operate within consistent systems. These systems are regulated by their environment and also qualities within the family itself"

The strength of the society is the family, how resourceful, ingenious, innovative and creative a society is viewed is the brain work of the family. Society does not develop, or progress more than the teachings, instructions, trainings, and tutoring's obtained from the family level. Likewise, the puissance of the family is the culture. This is the basis of family up bringing because is a way of life. Thus, culture is the wheel that drives the family vehicle. Whatever obtains in the society is based on the family values and the community culture and tradition. Family investiture is accessed in the society daily from the behavioural patterns of a child. While the daily accumulated behavioural patterns determines the worth of the society. So, the society is scaled and qualified by the daily actions of its citizenry which is an off shoot of their family training.

\subsection{Child Molestation in Nigeria}

There is no precise date of the emergence of child molestation in Nigeria; because at the inception most victims, and their parents/guardian were evasive because of the stigmatisation that is attached to it. Molestation comes in diverse forms such as sexual abuse, especially rape and incest are now on the rise in Nigeria. Currently, several Nigerians have lost their once prized values of decency and duty. In view of so many cases of adult males defiling young under-aged girls being widely recorded daily in both the Newspapers and television stations. Severally, these acts of infidelity of trust are executed mostly by nearneighbours, uncles, pastors, Imams, teachers, fathers etc. (World Health Organization (WHO 2003; 2006; Manyike et al., 2015).

Child abuse among children had been found to be caused by a decline in socioeconomic status, and the interruption of close relations. Child abuse was frequent in those from troubled and upset families and in those who also reported physical and emotional assault. Abuse among children may take several forms and vary in terms of frequency, duration, intrusiveness of the acts involved, and the use of force.

There are many commonalties among cultures, and each culture has unique aspects as well. A study on pediatrics HIV contagion from Sokoto posit that less than one percent of infections comes from sexual molestation. The effect of child sexual abuse is well written. It providesgreatlyin poor school performance, substance abuse, law-breaking, mental illness, suicide, and transmission of abusive behaviour to subsequent generations. Child abuse seen in childhood or adolescence is a devastating occurrence that can have serious, long-term psychosocial effects.

\subsection{Strategies for Families in Eradication of Child Molestation}

The Global Survey shows that children's safety from violence is gaining increasing attention on international, regional and national agendas. Our understanding on the reason why children are exposed to violence has extended, and strategic actions are coming in several countries to change this information into effective protection. Significant normative, policy and institutional developments have advanced national implementation of child protection approaches. There has been a revitalisation of networks to support advocacy, together with the development of strategic partnerships. This has 
helped to address attitudes and deeply rooted social norms condoning violence against children. This can also encourage the mobilisation of social support for this cause.

Despite these supposed interventions progress made has been slow, uneven and fragmented to make a real positive change in the protection of children from abuse. Eradication of violence against children demandsainternational effort on a bigger scale - an effort that includes political leaders as well as ordinary citizens, children and adults. The cost of neglect - for every child, and for nations' social progress - is simply too great to be ignored

\section{MethodOLOGY}

The researcher employs the qualitative research methodology to collect and analyse data; which helps the researcher to inquire and have deep understanding of meanings people give to things. The focus population is Nigeria, three regions were carefully selected among the six regions in the country. These represented the three major tribes in Nigeria namely the North west, South east and South west. For the Northwest Kano was selected. Southeast Nnewi was selected, and South west Ibadan was selected. A total of 75 persons were interviewed, 25 persons from each state. The focus people interviewed were parents, guardians, youths, and victims. Since it is not possible to interview the whole of Nigeria, this zonal representation was made to have a picture of the interest of the researcher.

\subsection{The Questionnaire}

The researcher made the use of (70) seventy questionnaires. They were administered in the Three chosen regions namely Kano, Nnewi and Ibadan. Twenty-five (25) questionnaires per State distributed in this order, (20) twenty distributed among parents, guardians, and youth while (5) five questionnaires was shared to victims. A total of (70) seventy questionnaires were collected and analised with narrative analyses.

\subsection{Data Presentation and Analysis}

Twenty-five (25) questionnaires were distributed within the Agbowo, Bodija, Ojo, and Olodo communities in Ibadan. Another (25) twenty-five questionnaires were distributed in Nnewi-nchi, Uruagu, Umudim, and Otobo communities in Nnewi town of Anambra State.Twenty-five (25) questionnaires were also distributed in Kabuga, Rijiya-zaki, Rijiya-lemu, Yan-kaba, in Kano. These questionnaires were distributed toparents, guardian, youth, and victimsin these communities. Most of the information's relating to sexual assault victims were gotten from the print medias as victims were not willing to divulge information because of the stigmatisation attached to it.

The researcher discovered different types of child molestation peculiar to the different regions. Southwest (Ibadan) common child molestation practices: child domestic helpers, child trafficking, touching of child private parts, rape, incest, child labour service in the market, emotional molestation by flogging and using abusive words on children. Child labour, hawking along the street.

Southeast (Nnewi) common child molestation practices: It was discovered that male child suffered more molestation in the east than the females. Male child was encouraged to registeras a trade apprentice at a tender age instead of going to school. Child trafficking- boys and girls especially from poor households were sent to cities as trade assistance and training traders in other to fend for their poor parents. Child begging - children are forced to lead their parents/guardiansin begging parade instead of going to school. Child molestation through health challenges- child with health challenge are meant to beg from city to city in the company of adult men; with the intention that the money collected will be used to carter for the child's health needs. Eventually money collected are shared among the men, little given to the parents of the child while the child health is left unattended to. Emotional molestation- flogging that has inflicted serious injuries on the child such as burnt, disabilities, death and madness etc.

Northwest (Kano)common child molestation practices: Child marriage- female child are betrothed at a younger age to men older to be their father or grandfather. (Almajiri) religious apprenticeshipchildren at tender age areenrolled under this schemeto learn the nitty-gritties of their faith, but alongside, their masters introduce them to begging in the street, in the communities, within/ outside the State. Thus, they were molested by being beaten up for flimsy excuses. While many of them are left to sleep outside on the street. Child hawking, rape, incest, child labour, Child trafficking- many 
young boys below the age of 18 were transported out of the state, and the region for manual jobs, child labour, hawking and as sales assistance.

The research discovered that these were socioeconomic problems which were the consequences of extreme poverty and lack. Which were more prevalent among those households who reside in clusters, slums, and are illiterate or semi-illiterate.

In the Southwest, it was gathered that molestation was as a result of the breakdown of cultural norms, family values and a neglect of traditions and customs; which resulted into a breakdown of societal morals. The age long practice of collectivism gave way to the modern practice of individualism in families. The family norms that sees every adult as "Egbon and Broder" has given way to the acceptance of the foreign word which addresses all adult male in the family as "uncle". The word "egbon/broder" has an intrinsic string that bond everybody in the family together. By so doing sexual molestation was not common because people seeeveryone as a family member no matter how distance the relationship is. It is a taboo to sexually molest any member of the family, nobody dears commit such sacrilege. The word "uncle" has a loose sense of belonging that sent a signal of distance relationship into people's mind, thereby encouraging unwholesome relationship. Also, modern day parents are too busy to teach and inculcate into their children, the family values, traditions, beliefs systems and practices; they are left in the hands of caregivers, watch cartoons without regulation, and videos where they imbibe unhealthy behavioural patterns that corrupt the society.

In the Southeast the enrollment of teenage boys in trade apprenticeship is a culturally accepted norms, so it was not seen as molestation but buildingself-dependence. This is done at the expense of acquiring western education. The long period of apprenticeship is a culture that encourages late marriage among male adult and give birth to sexual molestation. Furthermore, in the Northwest molestation is embedded in religion so this religious inclinationdoes not allow for public investigation of such act and for it to be seen as crime against children.

\section{CONCLUSION AND RECOMMENDATION}

The failure of the family has dire consequences on the society, which has led to child molestation in the country. This is because abandonment and poor children upbringing at the family level are the foundation of societal crimes such as child abuse/ child molestation. The study therefore recommends the production of cultural cartoons that showcase performances on positive cultural, traditional, and family ethic that will affect the society positively. The ministry of education should add to the secondary and primary school's curriculum teachings of cultural, traditional and family values. This approach will encourage youth, teenagers and pupilsin both Primary and Secondary schools to form cultural clubs such as jet clubs, literary and debate society. Again, it will increase their knowledge of cultural matters. Families and schools should always acknowledge publicly. Children who behave in a culturally acceptable manner toginger others with a view to emulating them. Adults from various families should establish a community based cultural club or a cultural NGO where parents / guardians can register their wards/children. A non-governmentalorganisation that is culturally based teaches and promotes positive hahaviour in the society. It is the view of the researcher that these approaches will positively change children's behaviour, influence the society and reduce to the barest minimum the recent surge of child molestation in Nigeria.

\section{REFERENCES}

[1] ANPPCAN. (1991). Charter on the Rights of the African child. Enugu: Chukas Press.

[2] Aderinto, A. A. (2000). Correlates and coping measures of street children: A comparative study of street and non-street children in South west Nigeria. Child Abuse and Neglect, 24 (9), 1199-1213. doi:10.1016/S0145-2134(00)00172-1

[3] Aderinto, A. A. (2010). Sexual abuse of the girl-child in urban Nigeria and the implications for the transmission of HIV/AIDS. Gender and Development, 5(2), 41-46.

[4] Ajuwon, A. J., Olaleye, A., Faromoju, B., \&Ladipo, O. (2006). Sexual behaviour and experience of sexual coercion among secondary school students in three states in North Eastern Nigeria. BMC Public Health, 6, 130-137. doi:10.1186/1471-2458-6-310

[5] Alabi, T., \& Alabi, O. S. (2012, March). Child labour amongst urban poor in Lagos and Abuja. Journal of Peace, Gender and Development, 2(3), 36-47

[6] Alabi, T., Bahah, M., \& Alabi, S. O. (2013). The girl child: A sociological view on the problem of girlchild education in Nigeria. Global Research Journal of Education, 3(2), 57-65. 
[7] Ebigbo P.O. (1990). The problems of child abuse and neglect in Nigeria and strategies for overcoming them. In Adebayo et al Nigeria Child. (eds), TheNigeria Child: Now and In the Future. Lagos: Larimex Printing Press.

[8] Ebigbo, P.O., (2003). Street child: The core of child abuse and neglect in Nigerian Children, Youth and Environment. 1-13.

[9] Ebigbo, P.O. (2006). Africa's children: Endangered everywhere. This Day. Retrieved from www.econassodates.com on 25th July 2006.

[10] Ebigbo, P.O.\&Isuora, G.I. (1985). Child labour in market places in the city of Enugu in bwibo, and onyango,. Children in Especially Difficult Circumstance Nairobi ANPPCAN.

[11] Elizabeth MS, Sandra P, Lara LM. The prevalence of sexual abuse among adolescents in school. J School Nurs. 2003;19. doi:10.1056/NEJM199710163371601

[12] Edu, D.O. \& Edu, G.O. (1999). Child abuse in Nigeria: Its impact on child development.

[13] Faye Dieme ME, Traore AL, Gueye SM, Moreira PM, Diouf A, Moreau JC. Sexual abuse: epidemiological, clinical aspects and management at gynecological and obstetrical department of DakarUniversity Hospital. J GynecolObstet Biol Reprod 2008; 37(4):358-64.

[14] Georgas, J. W. Berry, F. Van de Vijver, and Y. Poortinga), Families across Cultures (Cambridge: Cambridge University Press, 2006). Family, Self and Human Development across Cultures: Theory and Applications (Mahwah, NJ: Lawrence Erlbaum, 2007.

[15] Ikechebelu JI, Udigwe GO, Ezechukwu CC, Ndinechi AG, Joe Ikechebelu NN. Sexual abuse among juvenile female street hawkers in Anambra state, Nigeria. Afr J Reprod Health 2008; 12 (2):111-9.

[16] Irwin, L. G., Siddiqi, A., \& Hertzman, C. (2007). Early child development: A powerful equalizer. Final report for the WHO commission on the social determinants of health, pp. 5-67. Vancouver, BC: University of British Columbia.

[17] Obidigbo, G.C.E. (1999). The prevalence of child abuse nd neglect in our society: A case study of teachers in Enugu State of Nigeria. Ife Psychologia; 7, 2, 96-110.

[18] Olawale, S.G. (1995). Correlates of child abuse. Unpublished M. Ed Thesis. University of Ibadan.

[19] Olusanyan O. Ogbemi S., Unigbe J, Oronsaye A. The pattern of rape in Benin-City, Nigeria. Trop Geogr Med. 1986; 38(3):215-220.

[20] Manyike, P.C., J.M. Chinawa, E.O.O.I. Aniwada and T.A. Chinawa, 2015. Child sexual abuse among adolescents in Southeast Nigeria: A concealed public health behavioral issue. Pakistan Journal of Medical Sciences, 31(4): 827. Available at: https://doi.org/10.12669/pjms.314.7115.

[21] Togunde, D., \& Carter, A. (2008). In their own words: Consequences of child labor in Nigeria. Journal of Social Science, 16(2), 173-181.

Citation: Hannah Modupe Akpodiete. "The Synergy between Culture and Society in the Eradication of Child Molestation in Nigeria" International Journal of Humanities Social Sciences and Education (IJHSSE), vol 7, no. 10, 2020, pp. 88-93. doi: https://doi.org/10.20431/2349-0381.0710011.

Copyright: (C) 2020 Authors. This is an open-access article distributed under the terms of the Creative Commons Attribution License, which permits unrestricted use, distribution, and reproduction in any medium, provided the original author and source are credited. 